\title{
THE BIOLOGY AND ECOLOGY OF BRACHYCAUDUS DIVARICATAE SHAPOSHNIKOV (HEMIPTERA, APHIDOIDEA) ON PRUNUS CERASIFERA EHRHART IN WESTERN POLAND
}

\author{
Barbara Wilkaniec ${ }^{1 *}$, Agnieszka Wilkaniec ${ }^{2}$
}

Poznań University of Life Sciences, Dąbrowskiego 159, 60-594 Poznań, Poland

${ }^{1}$ Department of Entomology and Environmental Protection

${ }^{2}$ Department of Landscape Architecture

Received: July 30, 2012

Accepted: October 10, 2012

\begin{abstract}
Brachycaudus divaricatae - was described by Shaposhnikov in the Middle East as a heteroecious aphid species migrating between Prunus divaricata and Melandrium album. The research conducted in Poland proved that this species can be described as holocyclic and monoecious. A significantly shortened development cycle with a summer-winter diapause characterizes this species in Poland. The aim of our studies was a detailed research of the species biology conducted to explain this phenomenon. Elements of the biology and ecology of the new fauna species Brachycaudus divaricatae Shap., were studied in Poland during the 2008-2010 time period. The term of spring hatching, number of generations per season, development length of particular generations, lifespan of specimen, and fecundity of particular generations were all defined. The three-year study proved that 6 to 8 aphid generations can develop on P. cerasifera in Poland. The emergence of sexuales (amphigonic females and males) of $B$. divaricatae occurred very early in the season: in mid-May, and the first eggs were laid in June.
\end{abstract}

Key words: Brachycaudus divaricatae, cherry plum, demographic parameters, fecundity, life cycle

\section{INTRODUCTION}

So far, 4 species of Brachycaudus van der Goot, 1913 have been reported from plums (Prunus spp.) in Poland, namely: Brachycaudus cardui (Linnaeus, 1758), B. helichrysi (Kaltenbach, 1843), B. prunicola (Kaltenbach, 1843) and B. schwartzi (Börner, 1931) (Cichocka 1980). A new species, B. divaricatae (Shaposhnikov, 1956) was first reported in 2002, in the south-east of the country. This new species, was noted in considerable abundances on the trimmed hedges of the cherry plum in Lublin (Cichocka and Lubiarz 2003). Three years later, the species had already appeared in western Poland (Wilkaniec et al. 2007). An early seasonal occurrence of males came as a surprise, as this was very unusual for Poland. When monitoring aphid fauna in Poznań greenery in 2005 and 2006, B. divaricatae Shaposhnikov were caught in Moericke traps as early as 10th-20th June, while the males of other aphid species normally appear only in autumn. A detailed study of the species biology was conducted to explain this phenomenon.

\section{MATERIALS AND METHODS}

\section{Aphids reared in insectary conditions}

The research was carried out in insectarium (roofed building with walls of wire net and with dimension $3 \times 7 \times 3$ m) in the garden of the Department of Entomology, University of Life Sciences, Poznań, Poland, in the 2008-2010 time period. A single clone of the aphid, B. divaricatae was originally collected from a park area of Botanical Garden in Poznań, in May 2007. Aphids were reared on isolated shoots of two-year cherry plum (Prunus cerasifera Ehrhart) seedlings. Plants were grown in plastic pots with a $30 \mathrm{~cm}$ diameter in commercially used fertilized standard soil. Seedlings were watered as needed. Under each isolating nylon gauze cover, a single apterous viviparous female was placed on a shoot of a plant. The first larvae she bore started the next seasonal generation. Then, the female was moved under a new cover and her fecundity was studied. The pre-reproduction, reproduction and postreproduction periods in the lifespan of parthenogenetic females of particular generations were studied. The development of five apterous viviparous females was studied in each generation. The observations lasted from the end of March to the end of season aphid development.

The sexuparae generation was observed in the order of rearing amphiginic females and males. With this aim in mind, subsequent larvae were bred under separate isolators until they reached maturity.

In order to define a fecundity index for amphigonic females, a dissection of 30 mature females was performed. 
Melandrium album plants were tested as potential summer hosts. Plants were grown in plastic pots with a diameter of $15 \mathrm{~cm}$ in standard soil. Transfers of alate females were repeated at weekly intervals. A glass cylinder with nylon gauze on the top covered individual plants. The aphids were reared on these covered plants. Groups of five migrants were used for every transfer test.

\section{Aphids reared in controlled conditions}

Intrinsic growth rate $\left(\mathrm{r}_{\mathrm{m}}\right)$ was calculated with Wyatt and White's formula (1977):

$$
\mathrm{r}_{\mathrm{m}}=0.738 \mathrm{l}_{\mathrm{n}} \mathrm{M}_{\mathrm{d}} / \mathrm{d}
$$

where:

$\mathrm{d}$ - development period from birth to the beginning of the first reproduction,

$M_{d}$ - the number of nymphs born in the period from time $d$.

Rearing was carried out in a controlled environment at $20^{\circ} \mathrm{C}, 70 \%$ relatively humidity, and a $16: 8 \mathrm{~h} \mathrm{~L}: \mathrm{D}$ photoperiod in a climate chamber (Sanyo).
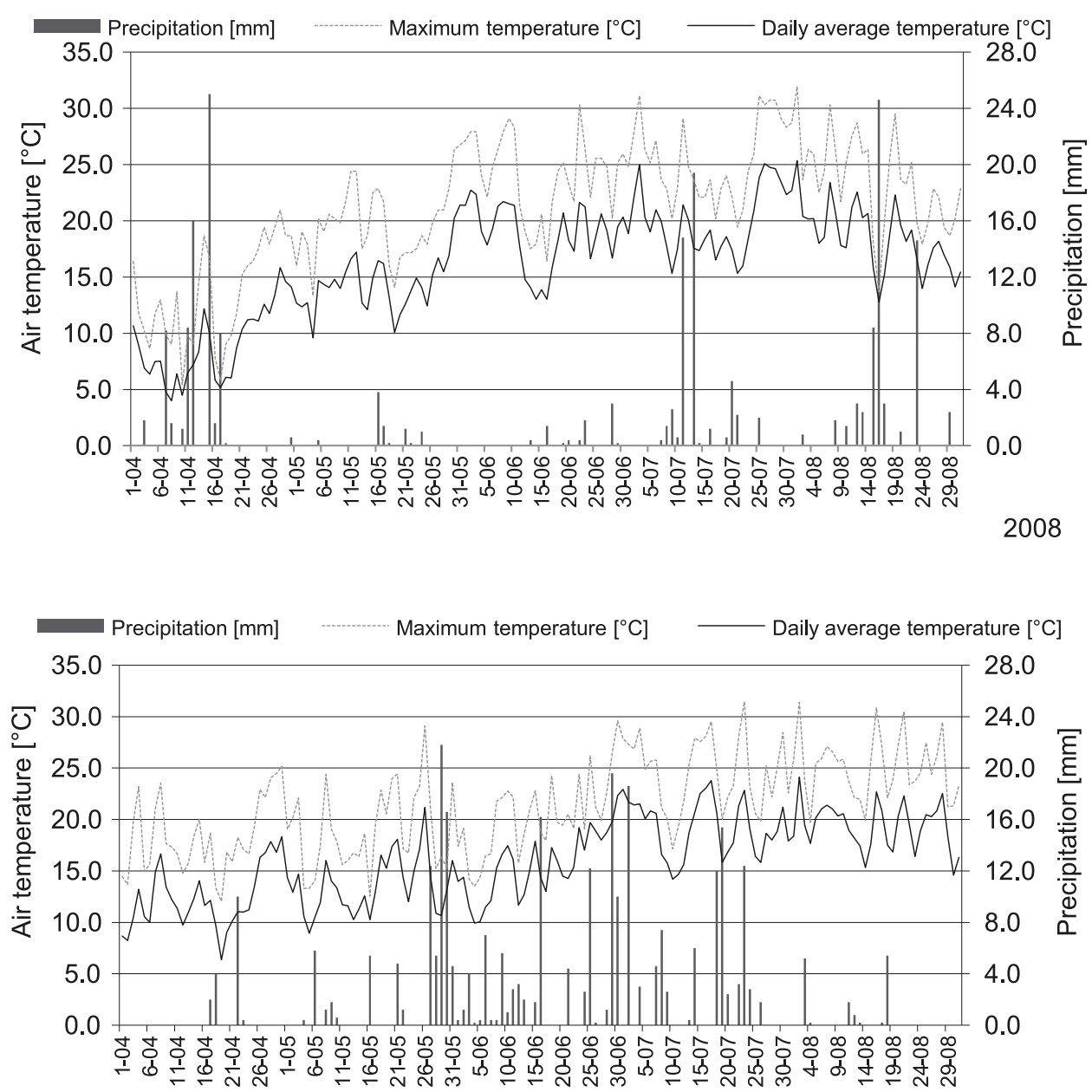

2009

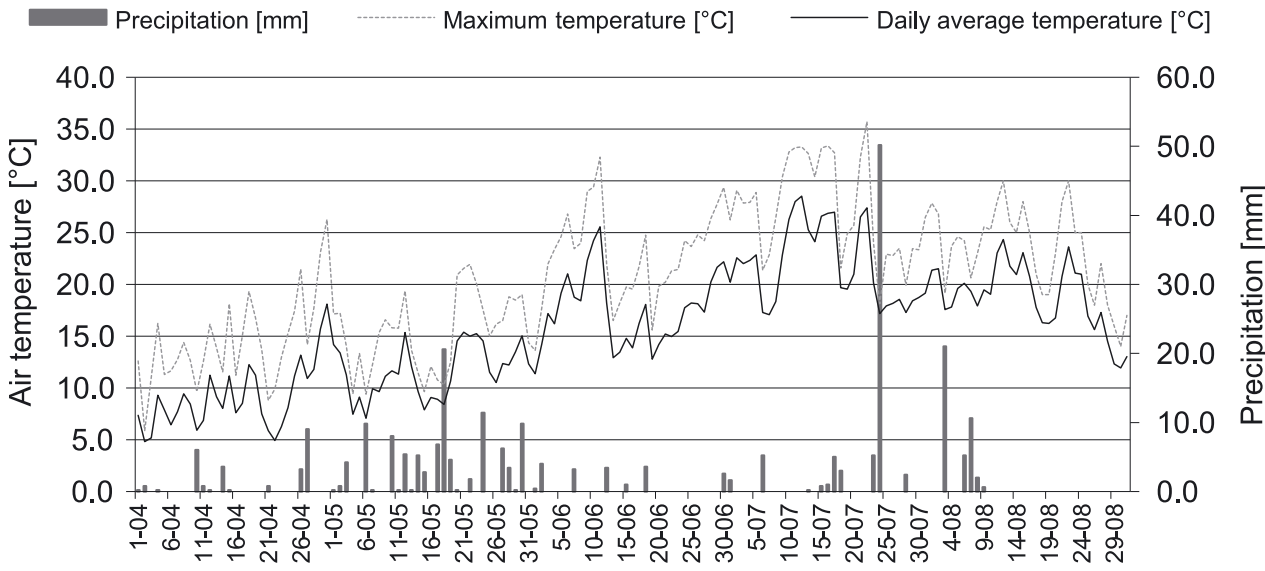

Fig. 1. Meteorological conditions in Poznan in the 2008-2010 time period 


\section{Field studies}

Phenology, abundance, and harmfulness of aphids were determined on shrubs of cherry plum, as elements of greenery in the urban environment and in ruderal habitats on the outskirts as well as farther outside the city. Observation were conducted between March and August in weekly intervals. All shoots of thirty shrubs of different ages were continuously observed.

\section{Meteorological conditions}

Meteorological data came from the Poznań-Marcelin Station located about $3 \mathrm{~km}$ from the place of study (Fig. 1).

\section{Statistical analysis}

The statistical analysis, conducted using a KruskalWallis test was used to examine the data on particular developmental stages generations as well as total lifespan and fecundity. The differences in developmental stages: pre-reproductive, reproductive, post-reproductive, total lifespan, and fecundity between subsequent generations in vegetation seasons were determined also using the Kruskal-Wallis statistical test. The data was analyzed separately for 2008, 2009, and 2010, and between years. To determine any relationship between developmental stages and temperature, non-parametric correlations (Spearman rank correlation) were used. Duration of prereproduction, reproduction, and post-reproduction periods; longevity and average maximum temperature and average daily temperature in 2008, 2009 and 2010 were examined. The data was statistically analysed using StatSoft, Inc. (2010), STATISTICA, version 9.0.

\section{RESULTS}

\section{Field studies}

In Poland, the fundatrices hatched from eggs at the end of March and the beginning of April. This was the period of the leaf bud-bursting stage of the cherry plum. Af- ter the fundatrices feed for several days, the young leaves turned from green to beige-pink and twisted strongly, which facilitated their spotting on bushes. During that time, a significant fall in the aphid population due to ladybirds was noted. Fundatrix maturity coincided with the full bloom of the bushes (10th to 20th April in 2008 and 2009, 20th to 30th April in 2010). Some of the parthenogenetic $B$. divaricatae generations developed in the season. The first alate parthenogenetic females were reported in large colonies as early as the beginning of June and their numerous abundance fell in mid-June. The first males were reported in colonies at the same time. Mass egg laying in the first two study seasons was noted in the last ten days of June, and, in 2010, at the end of June beginning of July. Amphiginic females only laid eggs on the bark of the trunk or on old branches of shrubs. The last live aphid specimens were observed in the middle of August on cherry plum shrubs.

In the field, a high level of cherry plum infestation was noted for all of the seasons. In mid-May, B. divaricatae sometimes infested $100 \%$ of the trimmed hedges of this shrub in Poznań parks. In 2009, at the end of May, the cherry plum shrubs in ruderal habitats on the outskirts and further outside the city had as many as $70-100 \%$ of fast-growing shoots infested and gravely damaged. The last developing colonies were observed in the field at the beginning of July, however, aphid feeding symptoms could be observed for a much longer period.

The symptoms of aphid feeding on shrubs were in the form of twisted, yellow leaves, later turning brown and drying into clusters, or even completely dried shoots.

\section{Insectary and laboratory studies}

The development of 6 to 8 parthenogenetic genetarions of $-B$. divaricatae was studied in the 2008-2010 seasons (Fig. 2).

Apterous parthenogenetic females of the first generation, i.e. fundatrices, lived the longest. This generation was also characterised by the longest development

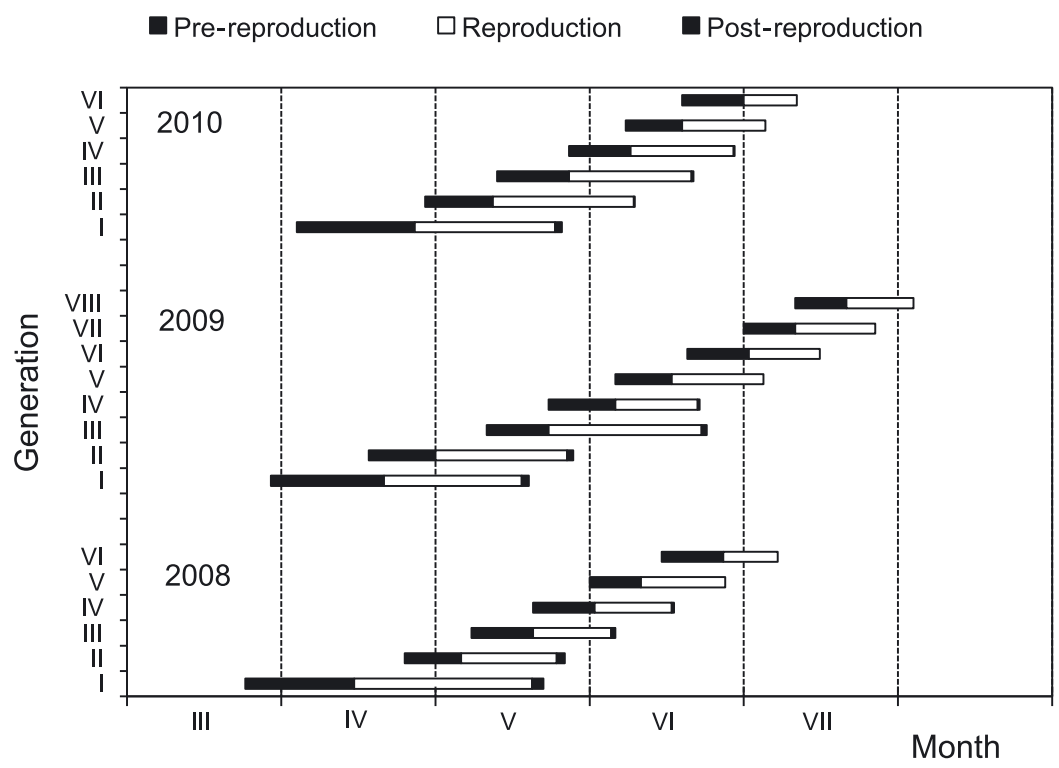

Fig. 2. The average length of the developmental stage of parthenogenetic females of B. divaricatae on P. cerasifera in the 2008-2010 time period 
periods, namely pre-reproduction, reproduction and post-reproduction, in comparison with the same periods of the next generations in season (Table 1). The average total lifespan of a fundatrix generation exceeded 50 days, with the pre-reproduction period in particular years averaging 21.2-23 days, the average reproduction period of 26.8-34.6 days and the average post-reproduction period of 1.2-2.2 days. Apterous viviparous females of the season's subsequent generations lived for a much shorter period of time than fundatrices. There was a tendency for a shortening of the reproduction stage. The total lifespan of the last generation of females in season was the shortest, and averaged 22.3-26 days.

Fundatrices bred only apterous viviparous females. However, among the offspring of the second generation and the next ones, sexuales appeared besides apterous and alate viviparous females. It was easy to distinguish male and female larvae by their colour: male larvae are light beige, while females are dirty red. In the first two study seasons, the first male larvae from the insectarium were reported as early as mid-May. In the last study season, they were noted at the end of May. Male larvae were also bred by parthenogenetic females of subsequent generations. The average length of the pre-reproduction period of males was 12 days. Amphygonic females developed simultaneously, although they took longer. The length of the pre-reproduction period of amphygonic females was 23-32 days. The first adult alate males appeared in the insectarium at the end of May, while females laid their first eggs after 10th June. Amphygonic females rarely laid eggs on the smooth bark of young shoots of cherry plum, instead they most often chose the gauze knots on the shoots.
Apterous viviparous females of the second generation and the following generations, bore female and male larvae in turn. The female included both alate and apterous parthenogenetic females and amphygonic females (oviparous females). Amphygonic female dissection showed the existence of 1-4 eggs in their bodies. Most often there were two eggs. Egg-laying females are small in size, almost twice as small as apterous viviparous females and dark red in colour.

Fundatrices were characterised by highest fecundity (Table 2). The most fertile female of this generation bore 184 larvae in the insectarium and lived 63 days. The average female fecundity in that generation in the 2008-2010 time period, exceeded 100 eggs. The fecundity of apterous parthenogenetic females of the next generations was significantly lower and in the last generation it dropped to several dozen larvae. Also, the total lifespan shortened to only 20 days, on average (Table 1$)$.

The intrinsic growth rate $\left(\mathrm{r}_{\mathrm{m}}\right)$ for $B$. divarivatae reared in controlled conditions was 0.228 \%/ $/$ /day.

In 2009, at the beginning of June, an attempt was made to introduce B. divarivatae on the Prunus domestica Stanley cultivar. The rearing in isolated conditions took only 1.5 months, during which time parthenogenetic females bore larvae, but by mid-July all the aphids were dead.

White campion (Melandrium album (Mill.) Garcke) is a herbaceous plant of Caryophyllaceae, described by Shaposhnikov (1956) as a summer host plant of the aphid species. Many attempts were also made to introduce alate parthenogenetic $B$. divaricatae onto white campion. All the attempts failed.

Table 1. Length of developmental stages of the apterous viviparous females of B. divaricatae on cherry plum in Poznań in 2008-2010

\begin{tabular}{|c|c|c|c|c|c|}
\hline \multirow{2}{*}{ Year } & \multirow{2}{*}{ Generation } & \multicolumn{3}{|c|}{ Average length of developmental stages in days } & \multirow{2}{*}{ Overall longevity } \\
\hline & & pre-reproduction & reproduction & post-reproduction & \\
\hline \multirow{6}{*}{2008} & 1 & $21.2(20-22)\left[2^{* *}, 5^{* * *}\right]$ & $34.6(32-38)\left[6^{* *}\right]$ & $2.2(0-3)$ & $58(52-63)\left[6^{* *}\right]$ \\
\hline & 2 & $11\left[1^{* *}\right]$ & $18.6(9-30)$ & $1.6(0-4)$ & $31.2(20-58)$ \\
\hline & 3 & 12 & $15.2(7-17)$ & $0.8(0-4)$ & $28(19-34)$ \\
\hline & 4 & 12 & $15(9-19)$ & $0,4(0-2)$ & $27.4(21-31)$ \\
\hline & 5 & $10\left[1^{* * *}\right]$ & $16.4(7-22)$ & 0 & $26.4(17-32)$ \\
\hline & 6 & 12 & $10.6(5-14)\left[1^{* *}\right]$ & 0 & $22.6(18-26)\left[1^{* *}\right]$ \\
\hline \multirow{8}{*}{2009} & 1 & $22\left[5^{* *}, 7^{* * *}\right]$ & $26.8(18-34)$ & 1.4 & $50.2(44-53)\left[6^{* *}, 7^{* *}\right]$ \\
\hline & 2 & $13\left[7^{* *}\right]$ & $25.6(16-37)$ & $1.2(0-5)$ & $39.8(29-50)$ \\
\hline & 3 & 12 & $29.8(23-34)\left[6^{*}\right]$ & $1(0-4)$ & $42.8(35-51)$ \\
\hline & 4 & $13\left[7^{* *}\right]$ & $16(11-20)$ & $0.4(0-1)$ & $29.4(24-34)$ \\
\hline & 5 & $11\left[1^{* *}\right]$ & $17.8(13-26)$ & 0 & $28.8(24-37)$ \\
\hline & 6 & 12 & $13.8(9-20)\left[3^{*}\right]$ & 0 & $25.8(21-32)\left[1^{* *}\right]$ \\
\hline & 7 & $10\left[1^{* * *}, 2^{* *}, 4^{* *}, 7^{* *}\right]$ & $15.6(10-20)$ & 0 & $25.6(20-27)\left[1^{* *}\right]$ \\
\hline & 8 & 10 & 13 & 0 & 26 \\
\hline \multirow{6}{*}{2010} & 1 & $23\left[4^{*}, 5^{* * *}\right]$ & $27.3(17-34)\left[6^{*}\right]$ & $1.3(1-2)$ & $51.6(41-58)\left[5^{* *}, 6^{* *}\right]$ \\
\hline & 2 & $13.2(12-14)$ & $27.4(26-31)\left[6^{*}\right]$ & $0,2(0-1)$ & $40.8(33-44)$ \\
\hline & 3 & $14\left[5^{*}\right]$ & $23.8(13-30)$ & $0.4(0-2)$ & $38.2(27-44)$ \\
\hline & 4 & $12\left[1^{*}\right]$ & $20(9-24)$ & $0.2(0-1)$ & $32.2(21-37)$ \\
\hline & 5 & $11\left[1^{* * *}, 3^{*}\right]$ & $16.2(10-22)$ & 0 & $27.2(21-30)\left[1^{* *}\right]$ \\
\hline & 6 & 12 & $10.3(9-12)\left[1^{*}, 2^{*}\right]$ & 0 & $22.3(21-24)\left[1^{* *}\right]$ \\
\hline
\end{tabular}

significance levels ${ }^{*} \mathrm{p} \leq 0.05,{ }^{* *} \mathrm{p} \leq 0.01,{ }^{* * *} \mathrm{p} \leq 0.001$ 
Table 2. Mean fecundity of apterous viviparous females of B.divaricatae on cherry plum in Poznan in 2008-2010

\begin{tabular}{|c|c|c|c|c|c|c|c|c|}
\hline \multirow{2}{*}{ Year } & \multicolumn{8}{|c|}{ Fecundity of females in generation } \\
\hline & 1 & 2 & 3 & 4 & 5 & 6 & 7 & 8 \\
\hline 2008 & $\begin{array}{c}137 \\
(54-184) \\
{\left[6^{* * *}\right]}\end{array}$ & $\begin{array}{c}91 \\
(63-115) \\
{\left[6^{* *}\right]}\end{array}$ & $\begin{array}{c}44.2 \\
(15-77)\end{array}$ & $\begin{array}{c}44.4 \\
(24-57)\end{array}$ & $\begin{array}{c}30.8 \\
(21-45)\end{array}$ & $\begin{array}{c}8.8 \\
(7-11) \\
{\left[1^{* * *}, 2^{* *}\right]}\end{array}$ & & \\
\hline 2009 & $\begin{array}{c}100.4 \\
(86-117) \\
{\left[6^{* *}\right]}\end{array}$ & $\begin{array}{c}96 \\
(58-118) \\
{\left[6^{* *}\right]}\end{array}$ & $\begin{array}{c}72.4 \\
(45-101)\end{array}$ & $\begin{array}{c}56 \\
(47-85)\end{array}$ & $\begin{array}{c}35 \\
(28-45)\end{array}$ & $\begin{array}{c}20 \\
(15-30) \\
{\left[1^{* *}, 2^{* *}\right]}\end{array}$ & $\begin{array}{c}39 \\
(19-76)\end{array}$ & 18 \\
\hline 2010 & $\begin{array}{c}114.3 \\
(79-151) \\
{\left[6^{* *}\right]}\end{array}$ & $\begin{array}{c}123.8 \\
(83-147) \\
{\left[5^{*}, 6^{* *}\right]}\end{array}$ & $\begin{array}{c}73.2 \\
(34-96)\end{array}$ & $\begin{array}{c}50.4 \\
(38-57)\end{array}$ & $\begin{array}{c}34.8 \\
(30-65) \\
{\left[2^{*}\right]}\end{array}$ & $\begin{array}{c}12.6 \\
(10-15) \\
{\left[1^{* *}, 2^{* *}\right]}\end{array}$ & & \\
\hline
\end{tabular}

significance levels ${ }^{*} \mathrm{p} \leq 0.05,{ }^{* *} \mathrm{p} \leq 0.01,{ }^{* * *} \mathrm{p} \leq 0.001$

\section{Statistical analysis}

The statistical analysis revealed significant differences in the development of particular aphid generations in 2008. Significant differences in the length of development were observed in the pre-reproductive stage between generations 1 and 2 , and 1 and $5(H=28.88 ; \mathrm{p}<0.01)$ (Table 1$)$, in the reproductive stage between generations 1 and $6(\mathrm{H}=15.06 ; \mathrm{p}<0.01)$ (Table 1$)$, in lifespan between generations 1 and $6(\mathrm{H}=15.74 ; \mathrm{p}<0.01)$ (Table 1$)$, and in fecundity between generations 1 and 6 , and 2 and $6(\mathrm{H}=$ 23.27; p < 0.01) (Table 2).

Significant statistical differences were observed between generations during the 2009 vegetation season. The differences mainly concerned the length of the prereproductive stage between generations 1 and 5, 1 and 7, 2 and 7 , and 4 and $7(\mathrm{H}=35.00 ; \mathrm{p}<0.01)$ (Table 1). Further statistical differences were observed in the 2009 data for the reproductive stage length between generations 3 and 6 $(\mathrm{H}=20.47 ; \mathrm{p}<0.05)$ (Table 1). Generations 6 and 7 differed significantly in their lifespan $(\mathrm{H}=24.68 ; \mathrm{p}<0.01)$ (Table 1$)$, and generations 1 and 6 , and also 2 and 6 differed significantly in female fecundity $(\mathrm{H}=27.35 ; \mathrm{p}<0.01)$ (Table 2).

Statistical differences were observed between generations during the 2010 season in the length of the prereproductive stage between generations 1 and 4, 1 and 5, and 3 and $5(\mathrm{H}=25.44 ; \mathrm{p}<0.05)$ (Table 1$)$; the reproductive stage between generations 1 and 6 , and 2 and $6(\mathrm{H}=$ 15.04; $\mathrm{p}<0.05$ ) (Table 1); lifespan between generations 1 and 5 , and 1 and $6(\mathrm{H}=20.49 ; \mathrm{p}<0.01)$ (Table 1$)$, and in female fecundity between generations 1 and 6, 2 and 5, and also 2 and $6(\mathrm{H}=21.10 ; \mathrm{p}<0.05)$ (Table 2).

Differences were also found between generations developing in 2008, 2009, and 2010: all generations were different in terms of the pre-reproductive stage $(H=12.15$; $\mathrm{p}<0.010$. In generation 3 , differences concerned the lifespan $(\mathrm{H}=8.51 ; \mathrm{p}<0.01)$, while in generation 6 - the fecundity $(\mathrm{H}=8.88 ; \mathrm{p}<0.01)$. There were no significant differences in the length of the reproductive stage and post-reproductive stage between generations in seasons.

The meteorological variables were closely correlated to pre-reproduction periods in 2008, 2009, and 2010. The average maximum temperature (2008: $\mathrm{R}=-0.353, \mathrm{p} \leq 0.01$; 2009: $\mathrm{R}=-0.526, \mathrm{p} \leq 0.001 ; 2010: \mathrm{R}=-0.340, \mathrm{p} \leq 0,01)$ and average daily temperature (2009: $\mathrm{R}=-0.499, \mathrm{p} \leq 0,001)$ were significantly negative-correlated with pre-reproduction of B. divaricatae.

\section{DISCUSSION}

B. divarivatae was described by Shaposhnikov in 1956 as a heteroecious species migrating optionally between $P$. divaricata (sometimes $P$. domestica or $P$. spinosa) and M. album (Caryophyllaceae), which originally occurred in Eastern Europe and the Middle East (the northern Caucasus, Transcaucasia, the Crimea, Turkmenia, Turkey, Iran) (Shaposhnikov 1956, Blackman and Eastop 1994). Rakauskas and Turčinavičienè (2006) stated that the species was reported in Lithuania in 2002 for the first time, to become an abundant taxon on cherry plum in subsequent years. Thus, the species travelled about 2,000 km towards the north-east from its original range. In 2002, the same year as in Lithuania, B. divaricatae was also reported for the first time from Lublin, (southeastern Poland) (Cichocka and Lubiarz 2003). Three years later, it was already recorded in Poznań, (western Poland) (Wilkaniec et al. 2007).

The research conducted in Lithuania (Rakauskas and Turčinavičiene 2006) proved that the species can be described as holocyclic and monoecious with a significantly shortened development cycle with summer-winter diapause. Research conducted in Poland proved the same status of the species, with only some differences in its phenology. These differences result mainly from the geographical location of Vilnius compared to Poznań. In Lithuania, males occurred in the rearing period in midJune (2004) before egg-laying females and the first eggs were laid on 24 June (2004). In our study, the first appearance of males was even a month earlier, i.e. in mid-May (2008 and 2009), and the first eggs were laid in the first ten days of June (2008). Unlike Lithuania, where development was possible until the end of the vegetation season and the first frost reaching $-10^{\circ} \mathrm{C}$, that stage was much shorter in Poland. The longest that live specimens in western Poland were observed, both in rearing and in the field, was until the beginning of August.

Shaposhnikov $(1962,1964)$ was of the opinion that a shorter development cycle resulted from a drastic decline in host plant quality. Such an explanation is difficult to confirm both in Lithuania and in Poland. It seems that males occurring very early in the season were reported in the period when the plant provided good conditions for development. Rakauskas and Turčinavičienè (2006) suggested another explanation: according to them an early 
occurrence of sexuales in the season proves there are genetic reasons behind the morphs.

As in Lithuania, an attempt to breed this species on $P$. domestica did not fully succeed. The aphids lived and reared in isolated conditions on the plum tree, for only 1.5 months.

On the other hand, contrary to the Lithuanian research, all attempts to introduce alate aphid parthenogenetic females on $M$. alba failed. The females did not bear larvae and died after a short time.

The results of the research conducted in Poland indicated that the species develops only on cherry plum without migration onto the summer host plant $M$. alba. Such unusual development with a long summer-winter diapause at an egg stage, significantly differs from the development of other local aphid species: where sexuales occur only in autumn.

Due to a wide range of the species host plant in Europe, it can be expected that the species will continue to migrate further across the continent. This would be the next known case of a Brachycaudus species migrating westwards after the case of B. iranicus Davatchi and Remaudiere, 1953, which came from the Middle East to Spain (Nieto Nafria et al. 1987).

\section{REFERENCES}

Blackman R.L., Eastop V.F. 1994. Aphids on the World's Tree. An Identification and Information Guide. CAB International \& The Natural History Museum, Wallingford, 986 pp.
Cichocka E. 1980. Mszyce roślin sadowniczych Polski. PWN, Warszawa, 119 pp.

Cichocka E., Lubiarz M. 2003. Aphids colonising cherry plum (Prunus cerasifera Ehrh.) trimmed hedges. Aphids and Other Hemipterous Insects 9: 37-43.

Nieto Nafria J.M., Munoz Martinez I., Mier Durante M.P. 1987. Pulgones (Hom. Aphidoidea) de la provincia de Soria, II: Aphididae. Boletin de la Asociacion Espanola de la Entomologia 11: 367-384.

Rakauskas R., Turčinavičienė J. 2006. Brachycaudus divaricatae Shaposhnikov, 1956 in Europe: biology, morphology and distribution, with comments on its taxonomic position (Hemiptera, Sternorrhyncha: Aphididae). Zoologische Reihe 82: 248-260.

Shaposhnikov G.K. 1956. Phylogenetic background of the system of the short tailed aphids (Anuraphidina) with reference to their host plants relationships. Trudy Zoologicheckogo Instituta 23: 215-320.

Shaposhnikov G.K. 1962. Aphids having shortened life-cycle and summer-winter diapauses. p. 79-95. In: "Discourses in Memory" (N.A. Cholodkovsky, ed.). Annual meetings, 11-14.

Shaposhnikov G.K. 1964. The aphides (Aphidinea) infesting Prunus divaricata and cherry species. Entomologicheskoje Obozrenije 43: 145-151.

Wilkaniec B., Ratajczak J., Sztukowska K. 2007. Aphid males in urban green space. Aphids and Other Hemipterous Insect 13: 83-90.

Wyatt I., White P.F. 1977. Simple estimation of intrinsic increase rwtes for aphids and tetranychid mites. J. Appl. Ecol. 14: 757-766. 